\title{
FRONTEIRA AMAZÔNICA: PASSAGEM OBRIGATÓRIA PARA HAITIANOS?
}

Sidney Antônio da Silva ${ }^{1}$

\begin{abstract}
Este artigo tem como objetivo analisar os significados da presença haitiana na fronteira Amazônica, buscando entender as reações a esta presença, seja da parte do governo brasileiro, seja da sociedade local, bem como explicitar a visão dos haitianos sobre o visto humanitário e suas expectativas sobre o Brasil. Nessa perspectiva, o conceito de "governamentalidade", o qual implica numa articulação entre as fronteiras sociais (boundaries) e as fronteiras físicas (borders), poderá nos ajudar a entender as contradições no gerenciamento deste fluxo migratório, deixando entrever que práticas de acolhimento são, na verdade, um desdobramento de práticas de controle migratório.
\end{abstract}

Palavras-chave: fronteiras, haitianos, visto humanitário, Amazônia.

A presença de haitianos nas fronteiras amazônicas, a partir de 2010, além de ser um fato novo na região, surpreendeu a todos, tanto o governo brasileiro quanto a sociedade civil. Para aquele, o primeiro desafio era definir-lhes um estatuto jurídico, já que ao chegarem naquelas fronteiras sem o visto de entrada, seja no estado do Amazonas ou no Acre, eles solicitam a condição de "refugiados" para permanecer de forma legal no Brasil. Caso contrário correriam o risco de serem barrados durante o percurso até Manaus ou de lá permanecer de forma indocumentada. Para a sociedade civil, o grande desafio foi prover-lhes acolhimento, sem as condições estruturais e econômicas para fazê-lo com dignidade. Nesse caso, a solidariedade de grupos religiosos ou não tem sido mais forte que a burocracia e a letargia de instituições governamentais, que tardaram em tomar medidas para gerenciar este fluxo migratório, provocando uma crise humanitária, primeiro em Tabatinga (AM), no final de 2011, e depois em Brasiléia (AC), no início de 2013.

1 Professor do Departamento de Antropologia e do Programa de Pós-Graduação em Antropologia Social da Universidade Federal do Amazonas-UFAM, Manaus, AM, Brasil. 
É a partir desse contexto que pretendemos analisar a presença haitiana na Fronteira Amazônica, particularmente em Tabatinga (AM) e Brasiléia (AC), com o objetivo de entender as reações a esta presença, seja da parte do governo brasileiro, seja da sociedade local, bem como a visão dos haitianos sobre o visto humanitário e suas expectativas sobre o Brasil. Nessa perspectiva, o conceito de "governamentalidade" proposto por Fassin", que vê uma particular articulação entre as fronteiras sociais (boundaries) e as fronteiras físicas (borders), poderá nos ajudar a entender as contradições no gerenciamento deste fluxo migratório, deixando entrever que práticas de acolhimento são, na verdade, um desdobramento de práticas de controle migratório. Isto quer dizer que, se por um lado, se concede aos haitianos um visto por "razões humanitárias", permitindo-lhes a inserção no mercado de trabalho, por outro, limita-se o acesso dos mesmos à cidadania plena, já que o referido visto tem prazo de validade e, para convalidá-lo, o requerente deverá comprovar vínculos empregatícios no Brasil. Nesse caso, o trabalho parece ser uma categoria central para entender a dinâmica deste fluxo migratório, que em apenas quatro anos, se faz presente em vários estados brasileiros, tanto nos grandes centros urbanos quanto em pequenas cidades do interior.

Os dados aqui analisados foram colhidos durante o trabalho de campo realizado em Tabatinga (AM), no final de 2011 e Brasiléia (AC), no mês de abril de $2013^{3}$. Em ambos os contextos a coleta de dados se deu mediante a aplicação de um questionário com perguntas semi-abertas, objetivando captar a percepção dos atores envolvidos naquela situação de conflito, a saber os haitianos, agentes governamentais e militantes da Pastoral do Migrante.

\section{A Fronteira e a experiência da liminaridade para os imigrantes}

Lugar de passagem de pessoas e de troca de bens materiais e simbólicos, fronteiras nacionais podem ter diferentes significados, dependendo da perspectiva de quem a cruza, seja na condição de turista ou como morador de alguma cidade fronteiriça. Para os que vivem nestas localidades, em geral, com infraestrutura precária e com baixa qualidade de vida, as fronteiras se transformam em periferia em relação aos centros de decisão e de desenvolvimento do país. Nessa perspectiva, elas seriam também "el espacio de la ausencia de significaciones sociales que marcan y demarcan al Estado-nación"4 . Contudo, do ponto de vista da geopolítica elas se transformam num lugar, não só de defesa de um possível inimigo, mas também de ataque, onde os interesses nacionais passam a ser uma

2 FASSIN, Didier. Policing Borders, producing boundaries the governmentality of immigration in dark times.

O trabalho de campo nessa cidade contou com o apoio financeiro do Instituto Brasil Plural - IBP.

4 GUIGOU, Lelio N. Acerca de fronteras, nominaciones y efectos teóricos, p. 76. 
questão de "Segurança Nacional". Como um lugar de passagem de pessoas, as fronteiras são lugares de controle de transeuntes e de migrantes pelos estados nacionais, que estabelecem uma hierarquia daqueles que são desejáveis ou não em seus territórios.

Do ponto de vista cultural, fronteiras nacionais, podem ser também, um espaço de "hibridação cultural" 5 , lugar de afirmação identitária e de múltiplas trocas simbólicas. Entretanto, do ponto de vista interno, o avanço da fronteira econômica, pode significar também a "degradação do Outro nos confins do humano" ; lugar de conflitos e de "friç̧ões interétnicas"7, diante da imposição de valores e interesses de grupos econômicos locais e internacionais. Seja como for, nos seus múltiplos sentidos, fronteiras só podem ser compreendidas em sua complexidade no plano das relações sociais.

Cruzar fronteiras nacionais tornou-se um ato comum num mundo interligado pelas redes de informação e pelas facilidades de locomoção, pelo menos para parte da população mundial, que o faz em função de diferentes interesses, como viagens de turismo, de negócios, em busca de novos conhecimentos, de experiências religiosas, por questões familiares, culturais, entre outros. Contudo para aquele que chega num marco fronteiriço sem um visto que o classifique para que veio, a situação é bem diferente.

No caso dos haitianos, vale lembrar que a entrada deles pelas fronteiras amazônicas não constitui uma "opção" a mais, já que o normal seria entrar por algum aeroporto brasileiro, pois, além de mais seguro, é também mais econômico do que fazer um longo percurso, que inclui vários países, entre eles a República Dominicana, o Panamá, o Equador e o Peru. Por essa rota, além dos gastos com a passagem é preciso enfrentar a intimidação e, em alguns casos, a violência de agentes policiais que atuam nas fronteiras do Peru e do Equador, tirando dos haitianos dinheiro e objetos pessoais. Tal rota acabou se consolidando em razão das dificuldades e pela demora na obtenção do visto na embaixada brasileira de Porto Príncipe. Para tentar atender esta demanda o governo brasileiro ampliou os lugares de emissão do visto em outros consulados, entre eles, o do Equador. Contudo, essa medida não teve como consequência o fim dessa rota, em razão da urgência que milhares de haitianos têm para conseguir um trabalho e enviar recursos para seus familiares. Nesse sentido, a rota amazônica, apesar de suas variações ao longo do tempo, em razão de medidas de controle emitidas pelos países de transito, e a solicitação da condição de "refugiado", passaram a ser uma

5 CANCLINI, Néstor García. Culturas hibridas.

6 MARTINS, José de Souza. Fronteira: a degradação do Outro nos confins do humano.

7 OLIVEIRA, Roberto C.; BAINES, Stephen G. (orgs.). Nacionalidade e etnicidade em fronteiras. 
estratégia de entrada, já que do ponto de vista legal o Brasil não pode negar-lhes tal solicitação, isto porque o país é signatário da convenção de Genebra de 1951.

Contudo, para o Conselho Nacional para os Refugiados - CONARE, os haitianos não estariam sofrendo algum tipo de perseguição política, religiosa ou étnica e em base a isso não encontra fundamento para deferir os pedidos de refúgio, encaminhando-os para o Conselho Nacional de Imigração - CNIg, que tem a função de resolver casos omissos, como é o caso dos haitianos. A saída encontrada pelo governo brasileiro foi conceder-lhes um visto humanitário com a validade de cinco anos, em razão da dramática situação social no Haiti, agravada ainda mais com o terremoto de 2010 (Resolução 97/2012). Trata-se, na verdade, de uma situação de grave e generalizada violação de direitos fundamentais, como o da alimentação, da moradia, da saúde, da educação e da segurança pessoal. Nessa perspectiva, de acordo com o Estatuto do Refugiado, lei 9794/09, eles poderiam ser reconhecidos enquanto tal.

Se, do ponto de vista jurídico, o governo brasileiro encontrou uma saída "humanitária", uma vez que reconhecê-los como refugiados aumentaria a sua responsabilidade para com eles e, além disso, abriria um precedente para outros grupos em situação semelhante, do ponto de vista dos direitos humanos o Brasil estaria negando o direito à solicitação do refúgio, já que depois da resolução 97/12 os pedidos de refúgio não eram mais enviados ao CONARE para serem apreciados, mas diretamente ao CNIg, com a alegação de que este procedimento encurtaria o tempo de concessão dos vistos. Nessa perspectiva, o visto humanitário nivela a todos na mesma condição de migrantes laborais em busca de trabalho, ignorando necessidades e interesses particulares, como a perseguição por razões políticas ou orientação sexual.

Já do ponto de vista social, a realidade que os haitianos tiveram que enfrentar nas fronteiras amazônicas se assemelha àquela dos campos de refugiados, onde grandes contingentes de pessoas convivem com o racionamento de alimentos e água e sem as condições mínimas de higiene e privacidade. Tal situação foi o resultado da falta de governança do governo federal, que demorou em tomar medidas para agilizar a emissão dos protocolos de solicitante de refúgio nas fronteiras amazônicas.

Vale notar que, no Estado do Amazonas, a quase totalidade do ônus da acolhida ficou por conta da sociedade civil que, através da Pastoral do Migrante, gerenciou esta questão, seja em Tabatinga ou em Manaus. Nessas cidades vale ressaltar a solidariedade de brasileiros, católicos ou não, que atenderam com presteza os pedidos de socorro feitos pelos agentes da referida Pastoral, os quais não sabiam como acolher tantos haitianos que todos os dias batiam nas suas portas, pedindo alojamento e orientação. 
Em Tabatinga a situação ficou insustentável depois da publicação da Resolução normativa 97, no dia 13 de janeiro de 2012, a qual proibia a entrada de haitianos sem o visto expedido na Embaixada Brasileira de Porto Príncipe, além de estabelecer o regime de cotas, limitando os vistos em até mil e duzentos por ano. Assim sendo, aqueles que entraram depois desta medida ficaram retidos na fronteira, enfrentando privações e insegurança, já que não podiam seguir caminho dentro do Amazonas, porque estavam indocumentados, nem serem deportados, já que de acordo com o princípio de non-refoulement, ou "não devolução" presente na Convenção de Genebra de 1951, o governo brasileiro não poderia tomar esta decisão. O confinamento na fronteira obrigou os haitianos a se manifestarem sobre esta situação, fazendo uma passeata silenciosa pelas ruas da cidade no dia 12 de janeiro de 2012, desafiando o próprio Estatuto do Estrangeiro (lei 6.924/81), que no artigo 107, inciso III, proíbe qualquer manifestação política de estrangeiros no Brasil.

Se, o objetivo da política de cotas era conter a entrada de haitianos pelas fronteiras amazônicas, "protegendo-os" da ação dos agenciadores ou coiotes ${ }^{8}$, como alegaram as autoridades brasileiras, tal medida parece não ter surtido efeito, já que eles continuaram percorrendo essa rota, apesar de todos os riscos e custos que ela implica. Isso indica a urgência que eles têm de conseguir um trabalho e enviar recursos a seus familiares. Pressionado pelas críticas negativas de diferentes setores da sociedade civil e dos próprios imigrantes, o governo brasileiro revogou o regime de cotas através da Resolução Normativa N. 102, no dia 26 de abril de 2013.

$\mathrm{Na}$ Fronteira acreana os reflexos de tais medidas foram ainda mais desastrosas para os imigrantes que lá estavam, já que com o fechamento daquela Fronteira um grupo de 245 haitianos ficou retido por três meses na pequena cidade peruana de Iñapari, enfrentando diferentes tipos de privações, entre elas a fome.

Com a abertura da Fronteira Amazônica eles continuaram entrando tanto pelo Acre, quanto pelo Amazonas, porém em menor número por essa rota. Se no Amazonas o governo não se envolveu com esta questão humanitária, alegando que os amazonenses tinham prioridade sobre os estrangeiros, no Acre tivemos o inverso. Tanto o governo estadual quanto o municipal assumiram o ônus e o gerenciamento da presença dos haitianos em Brasiléia, cidade com pouco mais

8 No Haiti aqueles que organizam as viagens supervalorizando-as e, às vezes, passam informações falsas e desaparecem com o dinheiro dos interessados na hora de partir são denominados pelos haitianos deraketè. Contudo, segundo Handerson (Diaspora. As dinâmicas da mobilidade haitiana no Brasil, no Suriname e na Guiana francesa, p. 164), aqueles que cumprem o prometido, acompanhando, inclusive, os viajantes em alguns trechos da viagem, são denominados por eles de ajans, ou agencia. Dessa forma, o serviço prestado por estes tem uma conotação profissional, já o do raketè, de cunho pejorativo, associando-se ao engano e ao roubo. 
de vinte e um mil habitantes, próxima à fronteira com a Bolívia. Nessa fronteira, basta atravessar a ponte sobre o rio Acre, a qual une as duas cidades, Cobija, capital do Departamento de Pando, e Brasiléia.

Já na fronteira com o Peru, depois de passarem por Cusco e Puerto Maldonado pela rodovia Transoceânica, chegam a Iñapari e cruzam a ponte da Amizade, onde há um posto da alfândega, em Assis Brasil. De lá vão até Brasiléia, geralmente em táxis, uma viagem que dura cerca de uma hora e meia para percorrer os cento e doze quilômetros que separam as duas cidades ${ }^{9}$. Nessa cidade, em abril de 2013, havia em torno de mil haitianos esperando pelo protocolo de solicitante de refúgio, documento que lhes permite tirar a carteira de trabalho e o cadastro de pessoa física na Receita Federal, o CPF.

O tempo de espera em Brasiléia variava de duas semanas a meses, dependendo da lista de espera que havia para ser atendido pela Polícia Federal na vizinha cidade de Epitaciolandia. No final do mês de abril de 2013, o governo federal organizou uma força tarefa para atender os haitianos naquela cidade, envolvendo os Ministérios da Justiça, Trabalho e Saúde. Vale notar, contudo, que esta medida só foi tomada depois que a Pastoral do Migrante de Porto Velho publicou um relatório sobre a situação aviltante a que eram submetidos esses "refugiados", alojados num galpão abandonado que fora adaptado para recebê-los na cidade.

Além dessas medidas governamentais, melhorias foram feitas no alojamento, como a colocação de reservatórios de água para beber e a construção de banheiros com chuveiros na parte externa do alojamento. Antes, havia banheiros químicos que exalavam um mau cheiro durante o dia, na medida em que o calor aumentava. Contudo, os problemas não se limitavam à falta de infraestrutura do local. Outras situações observadas apontavam para a violação de direitos fundamentais, como o direito a um descanso digno e à privacidade, já que homens e mulheres dormiam juntos em colchonetes espalhados pelo chão, sem nada para os proteger do vento frio da madrugada e da poeira que invadia o local. Além dessas situações de insalubridade, outro momento aviltante era o da alimentação, que era servida ao lado dos banheiros químicos e sem a distribuição de talheres. A solução encontrada pelos haitianos era transformar a tampa do marmitex em uma pequena espátula, para não ter que comer com as próprias mãos. A conjugação desses fatores criava um ambiente propício para o surgimento de doenças respiratórias e gástricas

9 Nesta Tríplice Fronteira há uma expectativa de mudanças com a abertura da rodovia Transoceânica ou "Estrada do Pacífico", sendo, portanto, uma passagem obrigatória para quem pretende ir ao Peru por terra. Sobre os possíveis impactos desta ligação do Brasil com o Pacífico, ver: VALCUENDE DEL RIO, José M.; CARDIA, Laís M. Frontera Brasil-Perú-Bolivia: la cuestión de la integración a través de la carretera Transoceánica en la Amazonia sur-ocidental. 
Se, por um lado, a situação limite vivenciada por todos feria a dignidade da pessoa humana, por outro, eles encontravam no universo da cultura e da religião uma forma de dar a volta por cima, através de atitudes como se arrumar segundo o costume para participar de um culto evangélico no próprio alojamento, o cuidado com a pele e os cabelos entre as mulheres, que faziam tranças umas nas outras, gesto que podia ser observado também entre os homens, quando alguém cortava o cabelo de um compatriota. Tais atitudes afastavam, ainda que por um momento, a falta de sentido numa situação de liminaridade e de falta de esperança.

Contudo, o que mais os preocupava era a falta de recursos próprios que Ihes permitisse seguir viagem para outras cidades brasileiras, onde, na visão deles, seria possível encontrar trabalho. Para aqueles que não contavam com recursos próprios, a solução era esperar por algum empregador que viesse contratá-los e bancasse a viagem até a cidade onde a empresa opera. Alguns entrevistados disseram que preferiam ir por contra própria, pois quando a empresa vai buscá-los, a proposta salarial é menor e o contratado assume uma dívida prévia e o compromisso de manter o vínculo empregatício com a contratante, fato que os deixava receosos.

No caso das mulheres com crianças o tempo de espera no alojamento era ainda maior, pois os empregadores priorizavam homens solteiros em razão da facilidade de alojá-los nos locais de destino. Se, num primeiro momento, a procura por essa mão de obra era intensa, com o passar do tempo ela foi diminuindo, talvez pela retração da demanda do próprio mercado de trabalho e também porque muitos haitianos assumiam o próprio ônus do deslocamento para outras cidades do Sudeste e Sul do Brasil, em razão das redes sociais que foram sendo criadas entre aqueles que já estavam no país e os recém chegados.

Uma forma de manter o contato com os que ficaram para trás e com aqueles que já estão no Brasil é o telefone celular. Era notória a quantidade de aparelhos em torno de uma tomada carregando suas baterias, alguns, inclusive, eram modelos de última geração. Outros levavam consigo tabletes e notebooks, indicando uma condição social diferenciada entre os haitianos que lá estavam, cujo acesso a esses bens de consumo pode ser o fruto de remessas ou de outras migrações já realizadas por eles mesmos, seja no âmbito do Caribe ou para a América do Norte.

Se, por um lado, o contato com o país de origem era possível, na medida em que tivessem dinheiro para recarregar os celulares, por outro, o contato com o contexto local era mínimo. A situação de confinamento já criava uma barreira com a população local que os via como "refugiados" que estavam de passagem. A língua era outra dificuldade, já que a maioria deles fala o créole 
como primeira língua e o francês como segunda ${ }^{10}$. Porém, aqueles que falam o espanhol, conseguiam se comunicar melhor. Nesse sentido, havia uma evitação e um certo desconforto com a presença deles, pois um contingente de mais de mil pessoas mudaria a rotina de uma pequena cidade como Brasiléia. Seus moradores viram suas praças, parques e a agência do correio serem ocupados por estranhos todos os dias. Já para os comerciantes, taxistas e companhias de transportes, a presença dos haitianos é bem-vinda, isto porque o uso por eles dessa modalidade de transporte significou um aumento no faturamento das empresas de transporte rodoviário.

Em razão de sucessivas denúncias feitas pela imprensa nacional, seja por entidades religiosas e defensoras dos direitos humanos, ou pelo próprio Ministério Público Federal, que apontou a violação de direitos fundamentais, ensejada pelas péssimas condições de alojamento, o abrigo em Brasiléia foi fechado em abril de 2014. Os que estavam naquela cidade foram transferidos para um alojamento provisório no parque de exposições agropecuária Marechal Castelo Branco em Rio Branco e depois para a chácara Aliança, um espaço usado anteriormente para eventos e lazer na periferia dessa capital. Diferentemente do alojamento de Brasiléia, esse espaço conta com dormitórios para homens e mulheres, espaço para refeições e uma ampla área verde, onde há um campo de futebol, espaço, aliás, fundamental para aliviar as tensões entre eles, já que a convivência com imigrantes de outras nacionalidades, entre eles, dominicanos, nem sempre é tranquila. Outra diferença que não pode deixar de ser remarcada é a localização desse abrigo. Se em Brasiléia o alojamento ficava numa área central da cidade, próximo à rodoviária e dos principais serviços, como correio, banco e posto de saúde, em Rio Branco tudo está distante, deixando entrever que este abrigo é mais um espaço provisório, nesta tentativa de gerenciar a passagem dos haitianos pelo Acre.

Vale notar a política adotada pelo governo daquele Estado, que é a de fornecer transporte gratuito aos haitianos e imigrantes de outras nacionalidades para se deslocarem de Rio Branco para São Paulo, fato que gerou controvérsia dentro dos diferentes níveis de governo. A chegada inesperada de um número expressivo desses imigrantes na capital paulista provocou atritos entre os governos do Acre e o de São Paulo, que através da sua secretária de Justiça, classificou

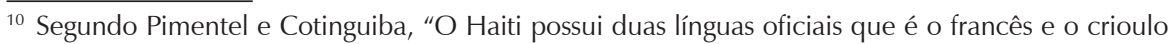
haitiano ou Kreyòl. Entretanto, nem sempre foi assim, por um longo tempo, apenas o francês figurava como língua oficial do país e somente em 1987 o crioulo foi reconhecido oficialmente. Assim, alguns estudos feitos convergem para a afirmação de que o Haiti é um país diglóssico, pois ao lado da língua vernácula (o Kreyòl), existe uma outra língua que é aparentada a esta, cujo status social é mais elevado (o francês)" (PIMENTEL, Marília Lima; COTINGUIBA, Geraldo C. Elementos etnográficos sobre imigração na Amazônia: inserção social de haitianos em Porto Velho, p. 41). 
de "irresponsável" a conduta do governo acreano ao facilitar a vinda de 400 haitianos em apenas quinze dias ${ }^{11}$.

Tal fato revela a falta de articulação das várias instâncias de governo na governabilidade da questão migratória no país, deixando entrever que a chegada de imigrantes pobres incomoda tanto aos governos estaduais e municipais, que veem suas políticas sociais questionadas, porque elas não incluem migrantes em situação de vulnerabilidade. O mesmo incômodo é perceptível em setores da sociedade local que veem nesta "invasão" de refugiados uma possível ameaça a seus empregos e à sua "tranquilidade" urbana. Além dessas implicações econômicas e sociais, havia também a ameaça sanitária, pois a morte de um haitiano diagnosticado como soro positivo colocou as autoridades sanitárias do Amazonas em alerta, diante de um possível aumento de infectados no Estado. Contudo, dados do Ministério da Saúde de 2010, indicavam que Manaus já ocupava antes da chegada dos haitianos o primeiro lugar entre as capitais brasileiras com a maior incidência de jovens infectados entre 15 e 24 anos. Tal pânico também fora constatado nos EUA no início dos anos 80, quando os haitianos foram acusados de disseminarem a Aids naquele país, cuja acusação se transformou, na verdade, num instrumento de estigmatização e exclusão do grupo de direitos fundamentais ${ }^{12}$.

Se, entre as autoridades sanitárias havia esta preocupação "profilática", na percepção do senso comum os haitianos representavam um "perigo" real, já que foram acusados de trazerem a aids, a malária e a cólera, doenças já existentes na Região Amazônica. Contudo, o "medo" dessa "invasão" de "refugiados" pobres e potencialmente doentes, adquiriu também uma conotação racial, já que para uma colunista social de Manaus, a cidade estava mais colorida com a presença dos haitianos ${ }^{13}$. Tais reações revelam, na verdade, que a retórica da "invasão" veiculada pela mídia local e nacional é a tentativa de se construir um estigma contra um determinado grupo de imigrantes para responsabilizá-los das mazelas já existentes na sociedade local, realidade, aliás, cada vez mais recorrente nos diferentes contextos internacionais, cuja atitude anti-imigrante é denominada de xenofobia. Contudo, é bom lembrar que a discriminação não se limita aos adultos, mas é extensiva também às crianças na forma do bullying, ridicularizando-as pela sua condição social e origem étnica, como é o caso dos filhos de bolivianos em São Paulo'4.

\footnotetext{
${ }_{11}$ Cf. <http://www1 folha.uol.com.br/cotidiano/2014/04/1444667>. Acesso em: 28.01.2015.

12 PINTO, Sónia Reis. A Migração de Haitianos para o Brasil e os usos da Razão Humanitária, p. 25.

13 SILVA, Sidney Antônio da. Aqui começa o Brasil: haitianos na Tríplice Fronteira e Manaus, p. 320.

14 IDEM. Bolivianos em São Paulo: Dinâmica cultural e processos identitários, p. 31.
} 
Após terem passado pelo "rito de passagem" na fronteira, a maioria dos haitianos e de outras nacionalidades, seguiu viagem para o Sudeste, Sul, Centro Oeste e até mesmo para o Nordeste. Na Região Norte as cidades que mais concentram haitianos são Porto Velho (RO) e Manaus (AM). Em que pese a pluralidade de motivos para emigrar, nesse caso é o trabalho que os move e cria a possibilidade de inserção nos diferentes lugares para onde migram, lembrando que o local de chegada pode não ser definitivo, mas um pretexto para novas partidas, já que, segundo Gaudemar ${ }^{15}$, é o capital que coloca em movimento a "força de trabalho", neste caso, em sua maioria, numa faixa etária produtiva. Dados de Silva ${ }^{16}$ apontam que a maioria deles se encaixa numa faixa etária que vai dos 20 aos 45 anos de idade; são do sexo masculino, apesar do aumento do número de mulheres; se declaram solteiros, embora muitos afirmam ter companheira e filhos no Haiti, e apresentam uma escolaridade média. Contudo, parte deles apresenta uma formação de nível técnico e uma minoria tem curso universitário completo ${ }^{17}$.

Tal perfil se encaixa, na verdade, no tipo do trabalhador(a) demandado por alguns setores da economia brasileira, como o da construção civil, da indústria, particularmente de alimentos, do comércio e de serviços. Tais atividades laborais estariam indicando também o lugar social reservado a estes imigrantes, "indesejados" socialmente, pelas camadas sociais "brancas", porém, necessários economicamente para a reprodução do capital. Apesar do mercado de trabalho enquadrá-los na categoria genérica de "trabalhadores" ou de "imigrantes haitianos", vale lembrar que eles apresentam especificidades, sejam elas de origem, sendo oriundos tanto do meio urbano, do Haiti e de outros países, quanto do rural, seja de ordem cultural, social e linguística.

\section{O visto humanitáriona visão dos haitianos}

Se para a maioria dos haitianos a passagem pelas Fronteiras Amazônicas foi traumática e marcada por violações de direitos fundamentais, resta pois saber qual é a visão deles sobre o visto humanitário e quais são suas expectativas sobre o Brasil. Para tanto nos valemos de entrevistas realizadas na cidade de Manaus em de 2014, nos bairros de São Geraldo e São Jorge, região centro-sul da cidade. Nosso objetivo era avaliar em parte a política de "acolhimento" adotada pelo Brasil em relação a esse grupo de imigrantes, já que é a primeira vez que se adota uma política "humanitária" no país, tendo como justificativa uma catástrofe natural. Quando perguntados como eles avaliam a situação propiciada pelo

\footnotetext{
${ }^{15}$ GAUDEMAR, Jean-Paul de. Mobilidade do Trabalho e Acumulação do Capital.

16 SILVA, Aqui começa..., op. cit.

17 Ibidem, p. 310.
} 
visto humanitário, a grande maioria respondeu que ela é satisfatória, porque o documento permite viver legalmente no país e trabalhar, fato que possibilita-lhes enviar recursos às suas famílias no Haiti. Segundo os entrevistados, os recursos enviados são utilizados principalmente para o sustento da família e o estudo dos filhos. Há quem consiga manter e até ampliar um negócio familiar. Já, para outros, os recursos têm uma finalidade migratória, ou seja, financiar passagens para a vinda de algum familiar para o Brasil, seja esposa, filhos, pais, irmãos e até mesmo parentes. Isto reforça a tese de que este fluxo migratório tem um caráter nitidamente familiar e que mandar buscar alguém do grupo é uma forma de honrar os compromissos assumidos na hora de partir. Contudo, a importância e o papel das redes familiares neste processo migratório, com base no parentesco, carecem ainda de uma análise mais aprofundada.

A média de recursos enviados gira em torno de U\$200 dólares mensais ( $R$ \$ 550 reais), o que representa uma grande ajuda às famílias que lá ficaram e para a economia de um país que depende, em grande parte, das remessas dos emigrados, cerca de $26 \%$ do produto interno bruto (PIB) ${ }^{18}$. O envio desses recursos é feito, em geral, através de agências de remessas de valores e bancos.

Contudo, para os que estão desempregados a percepção é pouco alentadora, pois segundo um entrevistado iletrado, o visto não serve para muita coisa, pois "não garante um emprego". A dificuldade para conseguir um trabalho, como resultado da falta de políticas de requalificação e a demora para a expedição da carteira de trabalho, talvez expliquem a avaliação regular ou péssima da atuação do Ministério do Trabalho.

Já, com relação ao apoio recebido no consulado brasileiro de Porto Príncipe as avaliações não foram tão positivas. A grande maioria avaliou o trabalho desse consulado como regular e péssimo, em razão das longas filas e do tempo de espera para solicitar o visto, fato que ajuda a explicar o porquê da "escolha" feita por eles pela rota amazônica.

Com relação às expectativas para o futuro, em que pese as dificuldades enfrentadas na Fronteira e o pouco tempo de permanência no Brasil, as opiniões se dividem entre aqueles que pretendem permanecer no país, trazendo, inclusive, algum familiar e aqueles que pretendem mudar-se para outra cidade brasileira, ou até mesmo para outro país, em busca de novas oportunidades. Entretanto, a volta ao Haiti também não está descartada, considerando que este retorno pode não ser definitivo, mas o ponto de partida para outra emigração, como é o caso dos Estados Unidos. A menção desse país por eles não é aleatória, considerando a histórica relação dos haitianos com a "América" e a imagem de

${ }_{18}$ Cf. <http://www.iadb.org/pt/noticias/artigos/2010-01-28/fluxo-de-remessas-e-mantido-no-haiti,6 481.html > . Acesso em: 04.02.2014. 
prosperidade que ela evoca no imaginário destes imigrantes, sendo considerado por eles como peyiBondye (o país de Deus) ${ }^{19}$.

Seja como for, é bom lembrar que a ideia do "retorno" ao lugar de origem, ainda que de forma temporária ou imaginária, é sempre um elemento presente nas trajetórias dos migrantes, que vivem a ambiguidade de uma dupla pertença: não ser daqui, nem ser de lá. Essa dupla pertença sinaliza, segundo Sayad $^{20}$, a ambiguidade presente na condição do migrante, a de "ser ignorada enquanto provisória, ao mesmo tempo, não se confessar enquanto transplante definitivo" ${ }^{\prime 21}$. Entre os haitianos a categoria diáspora expressa essa experiência de mobilidade e ganha diferentes significados, pois ela "designa pessoas, qualifica objetos, dinheiro, casas e ações"22. Nessa perspectiva, "diáspora" se transforma em substantivo, ou seja, numa categoria organizadora do mundo dos haitianos que vivem no exterior, os quais retornam temporariamente ao Haiti para rever parentes e amigos, bem como levar os bens adquiridos na diáspora. Por isso, não é estranho que eles a cumprimentem como se fosse uma pessoa: DiasporaKijan ou ye (Diáspora, como vai você).

Contudo, para os haitianos, a expressão mais eloquente do sucesso na diáspora é a construção da kaydiaspora (casa diáspora) no local de origem, em geral, num terreno da própria família. A casa deve ser grande e suntuosa para os padrões locais, como uma forma de suprir a ausência do emigrante e, ao mesmo tempo, remarcar o lugar social conquistado por ele com muito sacrifício, sujeitando-se, inclusive, a dividir uma casa com outros compatriotas no exterior. Isso indica que é preciso relativizar a ideia de mobilidade social, às vezes, essencializada por eles na diáspora. Vale notar, porém, que a construção da casa, seja no país de origem ou de residência, como expressão do sucesso migratório, não é uma exclusividade haitiana, mas é um elemento recorrente nos diferentes grupos de migrantes, sejam eles internos ou internacionais. $\mathrm{O}$ que varia são os tamanhos, os usos e as formas arquitetônicas incorporadas nos diferentes contextos migratórios.

Considerando a dinâmica da mobilidade haitiana pelo mundo, talvez seja cedo para fazer previsões sobre o futuro desta migração caribenha no Brasil, dado o curto prazo de sua trajetória no país. Do ponto de vista teórico também já não é mais possível analisá-la na perspectiva da permanência ou do retorno definitivo, supondo uma origem e um destino definidos para este fluxo, com seus fatores de atração e de expulsão. Desse ponto de vista, as categorias de emigrante e imigrante também já não dão conta da complexidade da realidade

\footnotetext{
${ }^{19}$ HANDERSON, op. cit., p. 37.

${ }^{20}$ SAYAD, Abdelmalek. A imigração e os paradoxos da alteridade.

${ }^{21}$ Ibidem, p. 46.

22 HANDERSON, op. cit., p. 37.
} 
migratória no mundo contemporâneo, considerando a emergência de processos sociais que vão além dos limites geográficos, culturais e políticos das sociedades neles envolvidos. Talvez a categoria "transmigrantes", proposta por Levitt e Glick-Schiller ${ }^{23}$, possa ampliar nossa compreensão sobre a dinâmica migratória empreendida pelos haitianos. Para esses autores, transmigrantes tomam decisões e estabelecem múltiplas relações capazes de unir num único campo social de ação as sociedades de origem, de acolhida ou de passagem. Nessa perspectiva, advertem os respectivos autores, que suposições sobre instituições sociais como a família, cidadania e estados-nações, devem ser repensadas a partir do contexto migratório ${ }^{24}$.

Isto posto, o caso dos haitianos e de outras nacionalidades, que se utilizam das rotas Amazônicas para entrar no Brasil em busca de refúgio e de oportunidades no mercado de trabalho, coloca em evidência os limites de uma política migratória e formas de acolhimento voltadas para migrantes em situação de vulnerabilidade, decorrentes de um marco regulatório restritivo e policialesco já ultrapassado e da falta de articulação entre as várias instâncias de governo que lidam com a questão migratória no país. Por mais paradoxal que possa parecer, o fato é que se um fenômeno natural, o terremoto no Haiti, foi utilizado pelo governo brasileiro para justificar a vinda dos haitianos ao Brasil, outro fenômeno natural, a enchente no Acre, se transformou em argumento social para barrar a entrada deles por aquela fronteira.

Isso revela que, enquanto uma nova legislação e política migratórias, fundadas na perspectiva dos direitos humanos, não forem aprovadas e implementadas, os imigrantes poderão estar sujeitos aos reveses de ações governamentais fragmentadas e de caráter emergencial, obscurecendo, dessa forma, o caráter humanitário que tais políticas de acolhimento pretendem ter.

\section{Bibliografia}

CAFFEU, Ana Paula; CUTTI, Dirceu. Só viajar! Haitianos em São Paulo: um primeiro e vago olhar. Travessia, n. 70, jan/jun 2012, p. 107-113.

CANCLINI, Néstor García. Culturas hibridas. São Paulo: Edusp, 1998.

FASSIN, Didier. Policing Borders, producing boundaries the governmentality of immigration in dark times. Annu. Rev. Anthropol., v. 40, 2011, p. 213-226.

FERNANDES, Duval; CASTRO, Maria da Consolação G. de. Relatório do Projeto "Estudos sobre a Migração Haitiana ao Brasil e Diálogo Bilateral". Organização Internacional para as Migrações - OIM, 2014. Disponível em: http://www.brasil. iom.int/.

\footnotetext{
${ }^{23}$ LEVITT, Peggy; GLICK-SCHILLER, Nina. Conceptualizing simultaneity - a transnational social field perspective on society.

${ }^{24}$ Ibidem, p. 157.
} 
FERNANDES, Jéssica S. Operação Haiti: ação humanitária ou interesse político para o Brasil? Conjuntura internacional, PUC Minas, 22 de março de 2010, p. 1-4.

GAUDEMAR, Jean-Paul de. Mobilidade do Trabalho e Acumulação do Capital. Lisboa: Editora Estampa, 1977.

GODOY, Gabriel G. de. O caso dos haitianos no Brasil e a via da proteção humanitária complementar. In RAMOS, André de Carvalho; RODRIGUES, Gilberto; ALMEIDA, Guilherme Assis de (orgs.). 60 anos de ACNUR: perspectivas de futuro. São Paulo: Editora CLA Cultural, 2011.

GUIGOU, Lelio N. Acerca de fronteras, nominaciones y efectos teóricos. In BASINI RODRIGUEZ, José E. et alii (orgs.). Fronteiras, diálogos e intervenção social no contexto Pan-Amazônico. Manaus: EDUA/FAPEAM, 2012, p. 75-85.

HANDERSON, Joseph. Diaspora. As dinâmicas da mobilidade haitiana no Brasil, no Suriname e na Guiana francesa. Tese de doutorado defendida no Programa de Pós Graduação em Antropologia Social do Museu Nacional- UFRJ, Rio de Janeiro, 2015.

KEARNEY, Michel. Borders and Boundaries of State and Self at the end of Empire. Journal of Historical Sociology, v. 4, 1991, p. 52-74.

LEVITT, Peggy; GLICK-SCHILLER, Nina. Conceptualizing simultaneity - a transnational social field perspective on society. In SAHOO, Ajaya Kumar; MAHARAJ, Brij. Sociology of Diaspora - a reader. India: Rawat Publications, 2007, p. 156-193.

MARTIN, Philip; MIDGLEY, Elizabeth; TEITELBAUM, Michael. Migration and development: whiter the Dominican Republic and Haiti? International Migration Review, Center for Migration Studies of New York, v. 36, n. 2, Summer 2002, p. 570-592.

MARTINS, José S. Fronteira: a degradação do Outro nos confins do humano. São Paulo: ed. Contexto, 2009.

MASSEY, Douglas et alii. Worlds in Motion: understanding international migration at the end of the millennium. Clarendon: Press Oxfrod, 1993.

MOULIN, Carolina. A política internacional da mobilidade: governamentalidade global e a produção da diferença no discurso disciplinar contemporâneo. In SILVA, Sidney A. (org.). Migrações na Pan-Amazônia: fluxos, fronteiras e processos sociais. São Paulo: Hucitec/FAPEAM, 2012, p. 275-288.

OLIVEIRA, Roberto C.; BAINES, Stephen G. (orgs.). Nacionalidade e etnicidade em fronteiras. Brasília: UNB, 2005.

PENTINAT, Susana B. El Estatuto jurídico de protección internacional de los refugiados ambientales. REMHU, Revista Interdisciplinar da Mobilidade Humana, v. 19, n. 36, jan./jun. 2011, p. 11-48.

PERUSEK, Glenn. Haitian emigration in the early Twentieth Century. Internacional Migration Review, v. XVIII, n. 1, 1984, p. 4-18.

PIMENTEL, Marília Lima; COTINGUIBA, Geraldo C. Elementos etnográficos sobre imigração na Amazônia: inserção social de haitianos em Porto Velho. Temas de 
Antropología y Migración, n. 7, Diciembre 2014, p. 31-55.

PINTO, Sónia Reis. A Migração de Haitianos para o Brasil e os usos da Razão Humanitária. Dissertação submetida como requisito parcial para obtenção do grau de Mestre em Antropologia. Lisboa, 2014.

PÓVOA NETO, Helion. Barreiras físicas como dispositivos de políticas migratórias na atualidade. In A Experiência Migrante. Entre deslocamentos e reconstruções. FERREIRA, Ademir P. et alii (eds.). Rio de Janeiro: Garamond, 2010, p. 491-520.

RICHMAN, Karen. A more powerful sorcerer: conversion, capital, and Haitian transnational migration. New West Indian Guide, v. 82, n. 1-2, 2008, p. 3-45.

ROSA, Renata de Melo. Subjetividade e inversão do racismo: um estudo de caso sobre os haitianos na República Dominicana. REMHU, Revista Interdisciplinar da Mobilidade Humana, Brasília, v. 18, n. 34, jan./jun. 2010, p. 99-112.

ROSA, Renata de Melo. Xenofobização da mulher negra migrante no processo de construção do feminino em emigração: a migração feminina haitiana em Santo Domingo. REMHU, Revista Interdisciplinar da Mobilidade Humana, Brasília, v. 15, n. 29, 2007, p. 71-86.

SAYAD, Abdelmalek. O Retorno: elemento constitutivo da condição do imigrante. Travessia, São Paulo, CEM, ano XIII, número especial, janeiro, 2000.

SAYAD, Abdelmalek. A imigração e os paradoxos da alteridade. São Paulo: EDUSP, 1998.

SCHILLER, Nina G.; BASCH, Linda; BLANC, Cristina S. From immigrant to transmmigrant: theorizing transnational migration. Anthropological Quartely, v. 68, n. 1, jan. 1995, p. 48-63.

SEGUY, Franck. A catástrofe de janeiro de 2010, a "Internacional Comunitária" e a recolonização do Haiti. Tese de Doutorado em sociologia defendida no Instituto de Filosofia e Ciências Humanas da Universidade Estadual de Campinas, 2014.

SILIÉ, Rubén. La nueva inmigración haitiana. Santo Domingo, República Dominicana: ediciones FLACSO, 2002.

SILVA, Sidney A. Aqui começa o Brasil: haitianos na Tríplice Fronteira e Manaus. In SILVA, Sidney A. (org.). Migrações na Pan-Amazônia - fluxos, fronteiras e processos socioculturais. São Paulo: Hucitec/FAPEAM, 2012, p. 300-322.

SILVA, Sidney A. Bolivianos em São Paulo: Dinâmica cultural e processos identitários. In BAENINGER, Rosana (org.). Imigração Boliviana no Brasil. Campinas: NEPO/ UNICAMP, 2012, p. 19-34.

SILVA, Sidney A. Brazil, a new Eldorado for Immigrants?: The case of Haitians and the Immmigration Policy. Urbanities, v. 3, n. 2, november 2013, p. 3-18.

SILVA, Sidney A. De 'refugiados' a Imigrantes: desafios à inserção sociocultural dos haitianos em Manaus. In SANTIN, Terezinha; BOTEGA, Tuíla (orgs.). Vidas em Trânsito. Conhecer e refletir na perspectiva da mobilidade humana. Porto Alegre: EDIPURCS; Brasilia: CSEM, 2014, p. 187-202.

SILVA, Sidney A. Nacionalidade e etnicidade na Tríplice Fronteira Norte. Cadernos 
CERU, v. 19, n. 1, jun. 2008, p. 33-48.

SPRANDEL, Márcia Anita. Algumas observações sobre fronteiras e migrações. Ciência e Cultura, v. 65, n. 1, 2013, p. 24-26.

STEPICK, Alex; PORTES, Alejandro. Flight into despair: A profile of recent haitian refugees in South Florida. Internacional Migration Review, v. XX, n. 2 1986, p. 329-350.

THOMAZ, Omar R. O terremoto no Haiti, o mundo dos brancos e o Lougawou. Novos Estudos CEBRAP, v. 86, 2010, p. 23-39.

VALCUENDE DEL RIO, José M.; CARDIA, Laís M. Frontera Brasil-Perú-Bolivia: la cuestión de la integración a través de la carretera Transoceánica en la Amazonia sur-ocidental. In CASAS MENDOZA, Carlos A.; ORTOLAN, María Helena; CARBAJAL, Claudia M. (orgs.). Olhares Histórico-Antropológicos sobre as Fronteiras na America Latina. Manaus: EDUA/FAPEAM, 2014, p. 335-363.

\section{Abstract}

\section{Amazon border: obligatory passage for Haitians?}

This article aims to analyze the meanings of the Haitian presence in the Amazon border, seeking to understand there actions to this presence, both, from the Brazilian government and the local society view. Besides of this, it pretends to explain the vision of Haitians on humanitarian visa and their expectations about brazilian labor market. From this context, the concept of "governmentality", which implies a link between social and physical boundaries, could help us understand the contradictions in the management of this migratory flow, showing that hosting practices are indeed an out spread of migration control policies.

Keywords: borders, Hatians, humanitarian visa, Amazon.

Recebido para publicação em 12/03/2015.

Aceito para publicação em 04/05/2015.

Received for publication in March, 12 ${ }^{\text {th }}, 2015$.

Accepted for publication in May, 04 $4^{\text {th }}, 2015$.

ISSN impresso: 1980-8585

ISSN eletrônico: 2237-9843

www. http://dx.doi.org/10.1590/1980-85852503880004408 